\title{
Type I spinal dural arteriovenous fistulas: historical review and illustrative case
}

\author{
Hendrik B. Klopper, M.D., Daniel L. Surdell, M.D., and William E. Thorell, M.D. \\ Department of Surgery, Section of Neurosurgery, University of Nebraska Medical Center, Omaha, Nebraska
}

\begin{abstract}
Type I spinal dural arteriovenous fistulas are the most common vascular malformation of the spinal cord, and an important cause of reversible progressive myelopathy. This lesion remains underdiagnosed, with most patients presenting late in the course of the disease. In this article the authors provide a review of the literature with particular attention to historical aspects related to the pathophysiology, diagnosis, classification, clinical findings, natural history, and treatment of this lesion. An illustrative case is also provided. (DOI: 10.3171/FOC.2009.26.1.E3)
\end{abstract}

KEY WoRds • dural arteriovenous fistula • spinal cord vascular malformation

- Type I dural arteriovenous malformation

A MONG spinal vascular malformations, the dural AVF, or Type I spinal AVM, is the most common and remains an underrecognized cause of progressive myelopathy. We provide a historical review of the literature pertaining to the pathophysiology, diagnosis, clinical findings, and treatment of this lesion along with an illustrative case.

\section{Early Case Descriptions and Treatment}

Hebold and Gaupp are credited with the first descriptions of isolated spinal cord vascular malformations in 1885 and 1888, respectively. ${ }^{3}$ Gaupp reported on the case of a 45-year-old woman with slowly progressive lower extremity weakness and paresthesias attributed to "a large varix of veins arising from the pia which pressed upon and flattened the spinal cord." 11 Over the next several decades, similar cases were reported in the literature as giving rise to symptoms closely resembling those of spinal tumors. Several of the reporting surgeons performed exploratory laminectomies in patients with progressive paraparesis who were subsequently found to have vascular malformations. According to Sargent, ${ }^{40}$ the first attempt at surgical treatment of 1 of these lesions was

\footnotetext{
Abbreviations used in this paper: $\mathrm{AVF}=$ arteriovenous fistula; $\mathrm{AVM}=$ arteriovenous malformation.
}

made by Krause in 1906. He ligated several tortuous vessels of the thoracic spine in a 34-year-old man who had presented with a 7-year history of progressive lower extremity symptoms. The patient died 3 months later, and at autopsy only remnants of spinal cord tissue were found at the operative site.

The first successful operation for a spinal cord vascular malformation was reported by Elsberg in $1916 .{ }^{16} \mathrm{He}$ described 6 cases of 120 laminectomies performed for spinal disease in which abnormally enlarged veins were found on the dorsal surface of the spinal cord at or near the symptomatic level. In 2 of these cases, significant improvement was noted after ligation of the abnormal vessels. One patient returned to normal neurological function 3 months postoperatively; this patient had presented with paraparesis and hemisensory loss referable to the T-9 level. At surgery a large posterior vein traversing the dura mater at the level of the T- 8 nerve root was ligated and resected.

Foix and Alajouanine ${ }^{20}$ described the pathology in 2 cases of progressive subacute necrotizing myelopathy in 1926. The spinal cords of these patients exhibited vascular thrombosis, spinal cord necrosis, and a dilated and tortuous surface vasculature. Thus, the entity of subacute or acute progressive myelopathy associated with abnormal spinal cord vasculature and necrosis in the absence of hemorrhage became known as the Foix-Alajouanine syndrome. Several groups later confirmed this association and the prevailing thought was that neurological de- 
terioration in these patients was attributable to a venous thrombotic event. $19,37,47,48$

Surgical treatment initially consisted of exploration with laminectomy alone, subsequent tacking open of the dura, and wound closure on discovery of abnormal intradural vasculature, electrocoagulation, or stripping of the abnormal vessels. The majority of outcomes were poor, although some authors reported a number of successes with stripping abnormal vessels from the surface of the cord. ${ }^{27,28,41}$ Ahead of his time, Sargent ${ }^{40}$ insightfully speculated that clinical findings in patients with these lesions were likely the result of circulatory disturbances in the spinal cord. He did make several attempts at ligating the abnormal veins but, hampered by an incomplete understanding of the pathophysiology of these lesions, concluded that the procedure "seems harmless but ineffective."

\section{Classification of Vascular Malformations}

The next significant advance in the diagnosis of spinal cord vascular malformations was brought about by the advent of selective angiography in the 1960s. The angiographic classification of the spinal cord vascular malformations signaled the beginning of the end for the hodgepodge of confusing and conflicting classification systems that had preceded it. Furthermore, it laid the groundwork for the modern surgical approach to these lesions. Di Chiro et al. ${ }^{13}$ and Baker and colleagues ${ }^{7}$ described 3 angiographic patterns, the most common of which were extramedullary and situated on the dorsal aspect of the spinal cord. This lesion was described as being fed by a single feeding artery in the majority of cases, with very sluggish flow being characteristic. These authors also observed intramedullary lesions, which were divided into the glomus type and juvenile type, both of which were noted to be much less common than the extramedullary variety. $7,13,14$

In 1977 Kendall and Logue ${ }^{24}$ published the first description of spinal AVFs. They reported on 9 cases of extradural spinal AVMs draining into the coronal spinal venous plexus, which had until then been an unrecognized entity. This group of patients resembled their previously reported series in demographics, manner of presentation, and clinical course, as well as myelography findings. The authors noted that the malformation derived its arterial supply from 1 or 2 segmental arteries and that all had 1 or 2 arterialized veins that penetrated the dura 2-3 $\mathrm{mm}$ from the nerve root sheath to drain into the coronal plexus of veins. These findings were substantiated by Merland and associates, ${ }^{33}$ Oldfield et al., ${ }^{36}$ and Symon et al., ${ }^{44}$ suggesting that lesions previously classified as extramedullary AVMs were in fact dural AVFs. Numerous subsequent classification systems have been proposed..$^{5,8,9,25} \mathrm{~A}$ commonly used system classifies dural AVFs as Type 1, intramedullary glomus-type AVMs as Type 2, intramedullary juvenile-type AVMs as Type 3, and intradural extramedullary malformations as Type $4 .^{13,18,23,30}$

\section{Clinical Findings and Natural History}

In 1974 Aminoff and Logue ${ }^{3}$ provided the first com- prehensive report of the clinical findings associated with spinal cord vascular malformations. In their series of 60 patients with myelographically, surgically, or necropsyproven spinal cord AVMs, $80 \%$ were in male patients, and $80 \%$ were older than 40 years of age. The authors found the lesions to be situated below the cervicothoracic junction in $88 \%$ of cases, with the vast majority of these being in the lower thoracic or thoracolumbar region. Aminoff and Logue also reported a significant disparity in presenting symptoms compared with those reported at the time of diagnosis. Nearly one-half of the patients had pain as their earliest symptom, although the distribution was somewhat nonspecific and included radicular pain as well as back pain. Only one-third of patients had lower extremity weakness as a presenting symptom, while another third had impaired sensation or paresthesias initially. Disturbances of micturition, defecation, or sexual function were evident initially in only $10 \%$. In contrast, by the time of diagnosis, $95 \%$ of patients had leg weakness, $93 \%$ had disturbed micturition, and $87 \%$ had sensory findings. Additionally, the authors found symptoms to be clearly exacerbated by exercise and relieved by rest.

The authors also published a report on the natural history of spinal cord vascular malformations based on their observations in the same cohort of patients. ${ }^{4}$ They proposed a functional grading scheme for assessing gait and micturition and performed follow-up in their cohort of patients for a mean of 8 years. The authors found that $19 \%$ of patients were severely disabled within 6 months of the onset of their motor disturbances. By 3 years, this number had grown to $50 \%$. At 3 years, only $9 \%$ of patients were capable of unrestricted activity. Furthermore, $68 \%$ of patients developed either mild or severe disturbances of micturition, and $55 \%$ developed moderate or severe disturbances of defecation; however, these findings were not clearly temporally related to the progression of motor disturbances.

Once it became evident that dural AVFs were a distinct clinicopathological entity, Rosenblum and coworkers $^{38}$ sought to compare these lesions with true intradural AVMs. They found that patients with intramedullary AVMs were younger at presentation than their counterparts with AVFs (average age at presentation 27 vs 49 years). The patients with intramedullary AVMs more commonly presented with hemorrhage, whereas those with AVFs were more likely to present with progressive paraparesis, as originally described by Aminoff and Logue. The AVMs were more commonly found in the cervical $^{3}$ or thoracic regions, and all of the AVMs shared a common blood supply with the spinal cord, a finding that was noted in only $15 \%$ of AVFs.

\section{Pathophysiological Characteristics}

After the recognition of spinal cord vascular malformations, a number of theories were advanced to explain the ultimate development of the associated clinical syndrome of complete or near complete spinal cord transection. Some early authors suggested that spinal cord compression by the abnormally dilated vessels was to blame. ${ }^{40}$ In his 1944 monograph, Wyburn-Mason ${ }^{48}$ noted that de- 


\section{Type I spinal DVFs: historial review and illustrative case}

compression was rarely, if ever, found to be beneficial. He proposed that thrombosis of the abnormal vessels was more likely the responsible mechanism.

Aminoff and colleagues ${ }^{2}$ were the first to consider spinal cord ischemia secondary to venous congestion/hypertension in intramedullary veins as a putative pathophysiological mechanism in these lesions. They discarded the idea of a vascular steal phenomenon due to the well-documented observation that the malformation and spinal cord only rarely share a common blood supply. Similarly, these authors felt that thrombosis was an unlikely mechanism given the slowly progressing course of the myelopathy and the lack of thrombus in pathological specimens obtained in patients with spinal cord vascular malformations. This view was supported by the recognition that AVFs cause arterialization of the coronal venous plexus. $^{24,28}$ Criscuolo et al. ${ }^{12}$ expanded on this concept and argued that the neurological manifestations of FoixAlajouanine syndrome are attributable to this pathophysiological mechanism, suggesting that, in contrast to the prevailing opinion at the time, the syndrome is reversible. Further support comes from a study in which the flow and pressure of intrathecal perimedullary draining veins in patients with dural AVFs were measured intraoperatively.22 The authors reported that the mean venous pressure prior to interruption of the fistula was $74 \%$ of systemic arterial pressure, and documented higher inflow and outflow velocities after interruption of the fistula.

\section{Diagnosis}

The early mainstay for diagnosis of dural AVF was exploratory laminectomy. Myelography was subsequently used with great success in identifying filling defects corresponding to dilated, tortuous vessels on the surface of the spinal cord. The sensitivity of myelography with postmyelogram CT scanning has been reported to be $100 \% .6,21,26,35$ Unless contraindicated, MR imaging has supplanted myelography as the diagnostic modality of choice. The most striking findings include increased signal within the spinal cord parenchyma on T2-weighted images with prominent subarachnoid vascular flow voids, which enhance prominently on administration of intravenous contrast medium. ${ }^{10,21,39}$ The abnormal flow voids are most commonly observed on the dorsal surface of the spinal cord. Spinal cord swelling and enhancement within the cord substance has been reported, and thus these lesions may mimic an intramedullary neoplasm. The utility of MR angiography has not been proven definitively, although it may be helpful in delineating the level of the fistula; first-pass contrast-enhanced MR angiography has been reported to be superior to conventional MR angiography in this regard. ${ }^{26,29,39}$

Spinal angiography is essential in defining the site of the fistula and for precise definition of the feeding artery and drainage pattern. This procedure can be technically challenging, particularly if a general idea of the level of the fistula has not been obtained by means of MR angiography or CT angiography. Some authors recommend aortography to narrow the search for the fistula, although a distinct disadvantage to this approach is that it limits the available contrast for subsequent selective injections. ${ }^{26}$ An argument has been made for the necessity of selective angiography of the entire vascular supply of the spinal dura mater. ${ }^{26,34}$ However, keeping in mind that multiplicity of dural AVFs is the exception rather than the rule and that in rare cases involving multiple feeding vessels they can be found within 1 level of each other, it is reasonable to limit selective angiography to 2 levels above and 2 levels below the lesion when evaluating for collateral supply, particularly when the venous drainage pattern matches that observed on the MR imaging or MR angiography. ${ }^{26,46}$

\section{Treatment Strategy}

The optimal treatment strategy for spinal dural AVFs remains to be defined. Current microsurgical treatment involves hemilaminectomy or laminoplasty with interruption of the intradural component of the arterialized vein as it enters the spinal canal through the intervertebral foramen. This approach has resulted in a $98 \%$ obliteration rate with a $<2 \%$ rate of morbidity. ${ }^{31,43}$ The reported complications are in accord with those expected with laminectomy.

$\operatorname{Logue}^{28}$ reported on the first series of patients who underwent surgical treatment by this approach. Gait disturbance was most likely to improve postoperatively, with $63 \%$ of patients showing some improvement. Of the patients who were chairbound preoperatively, $72 \%$ became ambulatory postoperatively. Bladder function and impotence were less likely to respond to intervention. Only $22 \%$ of patients had improved bladder function, but $65 \%$ stabilized at their preoperative level of function. No patients who were impotent showed any significant improvement after treatment. Of the patients with preoperative pain, $67 \%$ ultimately became pain-free. Two of the 24 patients in his series suffered neurological deterioration postoperatively. These results are in accord with subsequent studies. ${ }^{1,43,44}$

Studies addressing long-term follow-up are somewhat limited, but most studies with at least 1 year of follow-up have demonstrated that postoperative improvement or stabilization are sustained. The authors of one study noted initial improvement in accordance with other reports, but noted neurological deterioration in $63 \%$ of patients at a mean follow-up of 147 months. ${ }^{45}$ The reason for this deterioration is unclear, and the finding has not been duplicated. ${ }^{43}$

Endovascular therapy for a spinal AVMs was first undertaken by Dopmann in $1968 .{ }^{15}$ Several early studies involved embolization with polyvinyl alcohol, which has subsequently been shown to be a nonpermanent occlusive agent so we will not discuss them here. Studies in which modern occlusive agents have been used have shown disappointingly high recurrence rates ranging from 40 to $70 \% .{ }^{17,34,42,43}$ The complication rates are low, and are mostly related to the technical aspects of angiography. There is a paucity of studies with long-term follow-up after endovascular therapy, but it has been suggested that outcome in those with sustained fistula occlusion is comparable to outcomes observed after microsurgery. ${ }^{42,43}$ Microsurgery 


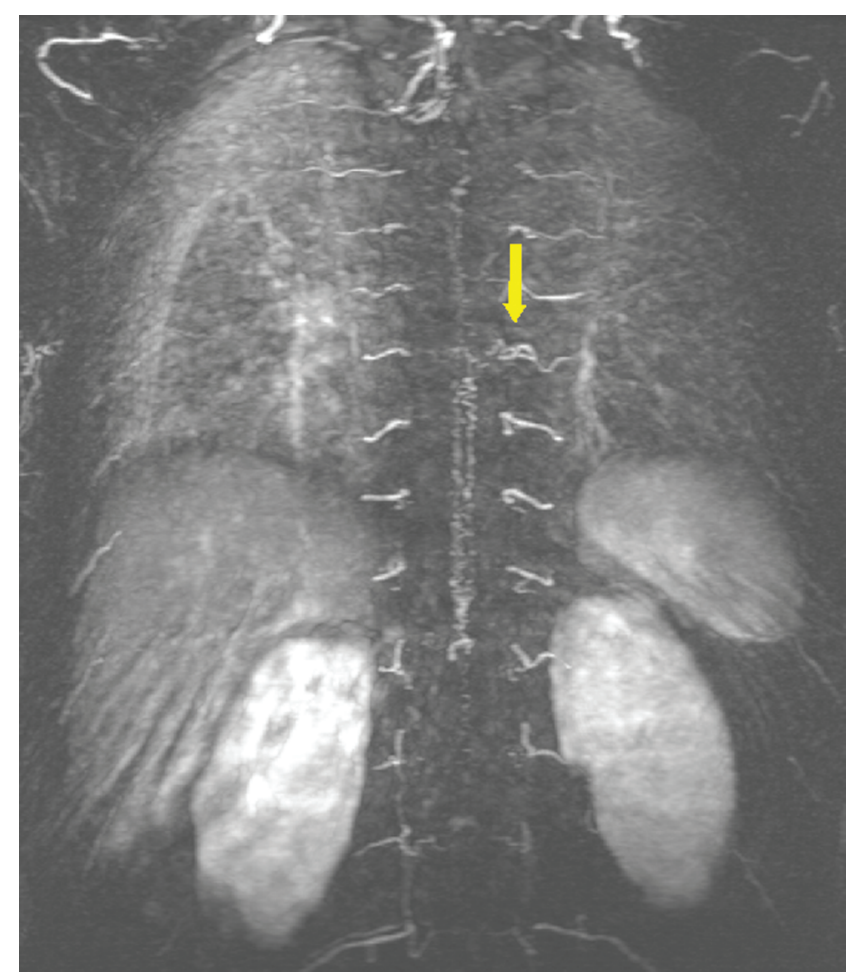

FIG. 1. Coronal MR angiogram of the thoracic spine in our patient illustrating the serpiginous draining vein within the spinal canal and the arterial feeding vessel near T8-9 on the left (yellow arrow).

is favored over endovascular therapy in cases in which the artery feeding the fistula is derived from branches that also supply the spinal cord and if selective catheterization of the pedicle is not technically feasible. ${ }^{32,46}$

Although endovascular therapy results in disappointingly high recurrence rates, the risks of embolization above and beyond those of spinal angiography seem to be minimal. Microsurgery, on the other hand, is a definitive treatment and also carries an acceptably low risk of complications. The treatment approach for patients with spinal dural AVFs should be decided on an individual basis, and decisions should ultimately be made by the wellinformed patient.

\section{Illustrative Case}

History and Examination. This 49-year-old, lefthanded man presented to our clinic with a 2-year history of left groin pain that radiated to his knee. He also reported bilateral foot pain and numbness for which he had initially sought the advice of a podiatrist. After noting proximal progression of the pain and numbness and increasing difficulty passing urine, the patient's primary care physician ordered unenhanced thoracic and lumbar spine MR images, leading to his referral. On further questioning, the patient related that he has also had increasing problems with balance and has had numbness on the dorsal aspect of his penis; there was no history of erectile dysfunction and the patient was able to ejaculate

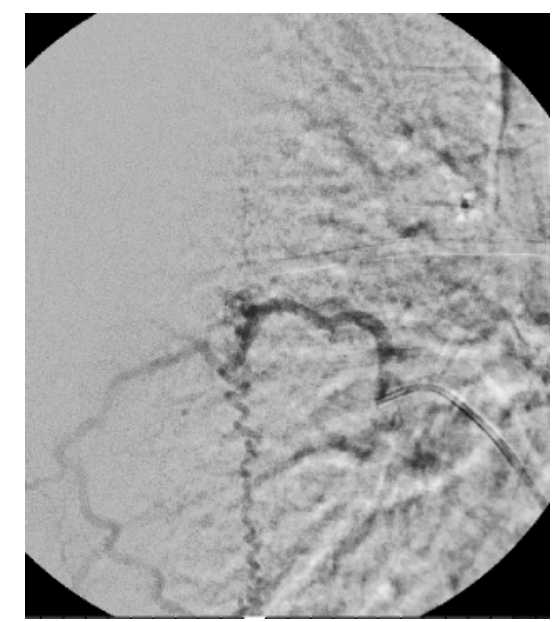

FIG. 2. Selective spinal angiogram. Anteroposterior view illustrates the radiculomedullary feeding artery at T-7 on the left with early and relatively slow filling of a tortuous venous structure running the length of the spinal cord.

normally. He had no history of hypertension, coronary artery disease, peripheral vascular disease, anemia, hypothyrodism, hyperthyroidism, or diabetes. His symptoms corresponded to a modified Aminoff-Logue score of 2 for gait and 2 for micturition.

On physical examination the patient had normal sensation, muscle tone, bulk, and strength in the upper extremities and diminished sensation throughout the lower extremities; lower extremity strength was $4+/ 5$ throughout. His patellar tendon reflexes were $3 / 4$ and symmetric, and the Achilles tendon reflexes were $2 / 4$ and symmetric. The plantar response was extensor bilaterally. $\mathrm{He}$ was noted to have a wide-based gait and a positive Romberg test. His examination was otherwise unremarkable.

Imaging Examination. Review of the MR images of the thoracic spine revealed prominent flow voids dorsal to the spinal cord, and hyperintense signal within the substance of the spinal cord from T-6 to T-12. The differential diagnosis at this stage included intramedullary tumor and spinal cord arteriovenous malformation. An MR angiogram of the thoracic spine was obtained (Fig. 1), which revealed dilated veins on the dorsum of the spinal cord with what appeared to be a AVF with a feeding vessel from the intercostal artery near the T8-9 level on the left side. Spinal angiography (Fig. 2) confirmed the presence of a spinal AVF with a feeding vessel at T-7 on the left.

Operation and Postoperative Course. Nine days later the patient was brought to the operating room for a T6-7 laminectomy with intraoperative motor evoked potential and somatosensory evoked potential monitoring. Intraoperatively a large arterialized vein was observed to penetrate the dura along the left T-7 nerve root sleeve. A temporary aneurysm clip was placed on the vessel and when no change was observed in the neurophysiological monitoring baseline, this was replaced with a permanent aneurysm clip. Intraoperative angiography confirmed complete disruption of the fistula.

The patient tolerated the procedure well, and was 


\section{Type I spinal DVFs: historial review and illustrative case}

discharged on postoperative Day 3 after an uncomplicated course. One month postoperatively the patient reported significant subjective improvement in his gait and strength, but he was having urinary retention requiring intermittent catheterization, and although he was able to attain an erection, he was unable to ejaculate. His urinary symptoms and strength gradually improved. At the most recent clinical visit 20 months after surgery, he was still bothered by numbness and paresthesias in the legs, remained unable to ejaculate, and continued to have mild hyperreflexia. His lower extremity strength, however, was noted to be normal. At that stage his modified AminoffLogue score was 1 for gait and 0 for micturition. The patient was able to continue his work as a heavy equipment operator.

\section{Disclaimer}

The authors report no conflict of interest concerning the materials or methods used in this study or the findings specified in this paper.

\section{References}

1. Afshar JKB, Doppman JL, Oldfield EH: Surgical interruption of intradural draining vein as curative treatment of spinal dural arteriovenous fistulas. J Neurosurg 82:196-200, 1995

2. Aminoff MJ, Barnard RO, Logue V: The pathophysiology of spinal vascular malformations. J Neurol Sci 23:255-263, 1974

3. Aminoff MJ, Logue V: Clinical features of spinal vascular malformations. Brain 97:197-210, 1974

4. Aminoff MJ, Logue V: The prognosis of patients with spinal vascular malformations. Brain 97:211-218, 1974

5. Anson JA, Spetzler RF: Classification of spinal arteriovenous malformations and implications for treatment. BNI Q 8:2-8, 1992

6. Atkinson JLD, Miller GM, Krauss WE, Marsh WR, Piepgras DG, Atkinson PP, et al: Clinical and radiographic features of dural arteriovenous fistula: A treatable cause of myelopathy. Mayo Clin Proc 76:1120-1130, 2001

7. Baker HL, Love JG, Layton DD: Angiographic and surgical aspects of spinal cord vascular anomalies. Radiology 88:1078-1085, 1967

8. Bao YH, Ling F: Classification and therapeutic modalities of spinal vascular malformations in 80 patients. Neurosurgery 40:75-81, 1997

9. Borden JA, Wu JK, Shucart WA: A proposed classification for spinal and cranial dural arteriovenous fistulous malformations and implications for treatment. J Neurosurg 82:166179, 1995

10. Bowen BC, Fraser K, Kochan JP, Pattany PM, Greene BA, Quencer RM: Spinal dural arteriovenous fistulas: Evaluation with MR angiography. AJNR Am J Neuroradiol 16:20292043, 1995

11. Cobb S: Haemangioma of the spinal cord associated with skin naevi of the same metamere. Ann Surg 62:641-649, 1915

12. Criscuolo GR, Oldfield EH, Doppman JL: Reversible acute and subacute myelopathy in patients with dural arteriovenous fistulas. Foix-Alajouanine syndrome reconsidered. J Neurosurg 70:354-359, 1989

13. Di Chiro G, Doppman JL, Ommaya AK: Radiology of spinal cord arteriovenous malformations. Progr Neurol Surg 4:329-354, 1971

14. Djindjian R: Angiographie de la moelle épinière. Paris: Masson, 1970, pp 109-110
15. Doppmann JL, Di Chiro D, Ommaya A: Obliteration of spinal-cord arteriovenous malformation by percutaneous embolization. Lancet 1:477, 1968

16. Elsberg CA: Diagnosis and Treatment of Surgical Diseases of the Spinal Cord and Its Membranes. Philadelphia: WB Saunders, 1916, pp 194-204

17. Eskandar EN, Borges LF, Budzik RF Jr, Putnam CM, Ogilvy CS: Spinal dural arteriovenous fistulas: Experience with endovascular and surgical therapy. J Neurosurg 96 (2 Suppl):162-167, 2002

18. Fessler RD, Deveshwar R: Neuroendovascular Surgery, in Rengachary SS (ed): Principles of Neurosurgery, ed 2. Edinburgh: Elsevier Mosby, 2005, pp 271-287

19. Flament J, Vicente AN, Coers C, Guazzi G: [Angiodysgenetic myelomalacia (Foix-Alajouanine) and its differentiation from spinal necrosis on intramedullary angiomatosis.] Rev Neurol (Paris) 103:12-29, 1960 (Fr)

20. Foix C, Alajouanine T: [Subacute necrotic myelitis.] Rev Neurol (Paris) 2:1-42, $1926(\mathrm{Fr})$

21. Gilbertson JR, Miller GM, Goldman MS, Marsh WR: Spinal dural arteriovenous fistulas: MR and myelographic findings. AJNR Am J Neuroradiol 16:2049-2057, 1995

22. Hassler W, Thron A, Grote EH: Hemodynamics of spinal dural arteriovenous fistulas. An intraoperative study. J Neurosurg 70:360-370, 1989

23. Heros RC, Debrun GM, Ojemann RG, Lasjaunias PL, Naessens PJ: Direct spinal arteriovenous fistula: A new type of spinal AVM. Case report. J Neurosurg 64:134-139, 1986

24. Kendall BE, Logue V: Spinal epidural angiomatous malformations draining into intrathecal veins. Neuroradiology 13:181-189, 1977

25. Kim LJ, Spetzler RF: Classification and surgical management of spinal arteriovenous lesions: arteriovenous fistulae and arteriovenous malformations. Neurosurgery 59 (5 Suppl): S195-S201, 2006

26. Koch C: Spinal dural arteriovenous fistula. Curr Opin Neurol 19:69-75, 2006

27. Krayenbuhl H, Yasargil MG, McClintock HG: Treatment of spinal cord vascular malformations by surgical excision. J Neurosurg 30:427-438, 1969

28. Logue V: Angiomas of the spinal cord: review of the pathogenesis, clinical features, and results of surgery. J Neurol Neurosurg Psychiatry 42:1-11, 1979

29. Luetmer PH, Lane JI, Gilbertson JR, Bernstein MA, Huston J III, Atkinson JL: Preangiographic evaluation of spinal dural arteriovenous fistulas with elliptic centric contrast-enhanced MR angiography and effect on radiation dose and volume of iodinated contrast material. AJNR Am J Neuroradiol 26:711-718, 2005

30. Malis LI: Arteriovenous malformations of the spinal cord, in Youmans JR (ed): Neurological Surgery. A Comprehensive Reference Guide to the Diagnosis and Management of Neurosurgical Problems. Philadelphia: WB Saunders, 1982, pp 1850-1874

31. Martin NA, Khanna RK, Batzdorf U: Posterolateral cervical or thoracic approach with spinal cord rotation for vascular malformations or tumors of the ventrolateral spinal cord. J Neurosurg 83:254-261, 1995

32. Merland JJ, Reizine D: Treatment of arteriovenous spinal cord malformations. Semin Intervent Radiol 4:281-290, 1987

33. Merland JJ, Riche MC, Chiras J: Intraspinal extramedullary arteriovenous fistulae draining into the medullary veins. J Neuroradiol 7:271-320, 1980

34. Narvid J, Hetts SW, Larsen D, Neuhaus J, Singh TP, McSwain H, et al: Spinal dural arteriovenous fistulae: Clinical features and long term results. Neurosurgery 62:159-167, 2008

35. N'Diaye M, Chiras J, Meder JF, Barth MO, Koussa A, Bories J: Water-soluble myelography for the study of dural arterio- 


\section{H. B. Klopper et al.}

venous fistulae of the spine draining in the spinal venous system. J Neuroradiol 11:327-339, 1984

36. Oldfield EH, Di Chiro G, Quindlen EA, Rieth KG, Doppman JL: Successful treatment of a group of arteriovenous malformations by interruption of dural fistula. J Neurosurg 59:1019-1030, 1983

37. Pia HW, Vogelsang H: [Diagnosis and treatment of spinal angiomas.] Dtsch Z Nervenheilkd 187:74-96, 1965 (Ger)

38. Rosenblum B, Oldfield EH, Doppman JL, Di Chiro G: Spinal arteriovenous malformations: a comparison of dural arteriovenous fistulas and intradural AVM's in 81 patients. J Neurosurg 67:795-802, 1987

39. Saraf-Lavi E, Bowen BC, Quencer RM, Sklar EM, Holz A, Falcone S, et al: Detection of spinal dural arteriovenous fistulae with MR imaging and contrast-enhanced MR angiograpy: sensitivity, specificity, and prediction of vertebral level. AJNR Am J Neuroradiol 23:858-867, 2002

40. Sargent P: Haemangioma of pia mater causing compression paraplegia. Brain 48:259-267, 1925

41. Shepherd RH: Observations on intradural spinal angiomas. Neurochirurgica 6:58-74, 1963

42. Song JK, Viñuela F, Gobin YP, Duckwiler GR, Murayama Y, Kureshi I, et al: Surgical and endovascular tx of spinal dural arteriovenous fistulas: long-term disability assessment and prognostic factors. J Neurosurg 94 (2 Suppl):199-204, 2001

43. Steinmetz MP, Chow MM, Krishnaney AA, Andrews-Hinders D, Benzel EC, Masaryk TJ, et al: Outcome after treatment of spinal dural arteriovenous fistulae: a contemporary singleinstitution series and meta-analysis. Neurosurgery 55:77-88, 2004

44. Symon L, Kuyama H, Kendall B: Dural arteriovenous malformations of the spine. Clinical features and surgical results in 55 cases. J Neurosurg 60:238-247, 1984

45. Tacconi L, Lopez Izquierdo C, Symon L: Outcome and prognostic factors in the surgical treatment of spinal dural arteriovenous fistulas: a long term study. Br J Neurosurg 11:298305, 1997

46. Veznedaroglu E, Nelson PK, Jabbour PM, Rosenwasser RH: Endovascular treatment of spinal cord arteriovenous malformations. Neurosurgery 59 (5 Suppl):S202-S209, 2006

47. Wirth FP Jr, Post KD, Di Chiro G, Doppman JL, Ommaya AK: Foix-Alajouanine disease. Spontaneous thrombosis of a spinal cord arteriovenous malformation: a case report. Neurology 20:1114-1118, 1970

48. Wyburn-Mason R: The Vascular Abnormalities and Tumours of the Spinal Cord and its Membranes. Saint Louis: CV Mosby, 1944

Manuscript submitted September 16, 2008.

Accepted October 22, 2008.

Address correspondence to: Hendrik B. Klopper, M.D., Residents Section of Neurosurgery, University of Nebraska Medical Center, 982035 Nebraska Medical Center, Omaha, Nebraska 68198-2035. email: hklopper@unmc.edu. 